\title{
Awareness of various aspects of diabetes among people visiting tertiary eye care institute in north India
}

\author{
Shikha Sharma ${ }^{\mathrm{a}}$, Jayendra Jha ${ }^{\mathrm{a}}$, Abhishek Varshney ${ }^{\mathrm{b}, *}$, Lokesh Chauhan ${ }^{\mathrm{c}}$ \\ ${ }^{a}$ Department of Clinical Optometry and Visual Sciences, C L Gupta Eye Institute, Ram Ganga Vihar, Phase 2 (Ext), Moradabad, 244001, India \\ ${ }^{\mathrm{b}}$ Department of Vitreoretina, C L Gupta Eye Institute, Ram Ganga Vihar, Phase 2 (Ext), Moradabad, 244001, India \\ ${ }^{\mathrm{c}}$ Department of Clinical Research, C L Gupta Eye Institute, Ram Ganga Vihar, Phase 2 (Ext), Moradabad, 244001, India
}

\section{A R T I C L E I N F O}

\section{Keywords:}

Diabetes

Diabetic retinopathy

Awareness

North India

Complications

Uttar Pradesh

\begin{abstract}
A B S T R A C T
Purpose: The aim of this study was to assess the awareness of the people visiting eye care institute with various aspects of diabetes.

Method: Cross sectional survey was carried out during January to March 2018. Survey instrument was developed with the help of experienced faculty, and literature review. Random sampling was done to identify individual. Participants were considered aware if they were aware of the fact that diabetes could be identified by blood or urine tests. Participants were considered diabetics if they reported being on medication for diabetes. Data was collected by means of personal interview with the participants.

Result: 530 participants were interviewed. A total of $482(90.9 \%)$ participants were aware of diabetes. Of them, 156 (32.4\%) respondents were diabetics, and 326 (67.6\%) were non diabetics. Overweight 156 (32.4\%), and family history $119(24.7 \%)$ were the most common risk factor identified by participants. Among complications, the kidney was cited by 218 (45.2\%), and eyes was cited by $228(47.3 \%)$. Only 40 (25.6\%) diabetic, and 45 $(13.8 \%)$ non diabetic participants were aware about diabetic retinopathy. $201(41.7 \%)$ participants knows that taking healthy food can prevent diabetes. Knowledge about diabetes (34.4\%) and time (29.3\%) were identified as major barrier to diabetes screening.

Conclusion: This study shows that the majority of people visiting a tertiary eye care institute were aware of diabetes. However their knowledge about its risk factors, complications, prevention, and management was poor. Integrated approach among various healthcare providers is required in creating awareness about all aspects of diabetes.
\end{abstract}

\section{Introduction}

Non-communicable diseases (NCD) like diabetes mellitus, cardiovascular diseases, cancer, and chronic respiratory diseases are the leading cause of disability and mortality globally. ${ }^{1,2}$ Rising prevalence of DM is a global challenge to public health. The expected number of diabetic patients will rise to 642 million by $2040 .^{3}$ In 2011, India had 62.4 million people with diabetes. ${ }^{4}$ The overall prevalence of diabetes in India was $7 \cdot 3 \% .^{5}$ Prevalence of diabetes was found to be higher among males in south India, and among females in north India. ${ }^{6,7}$ The association of diabetes with socioeconomic status has been changing. Previously diabetes has been considered to be associated with higher socioeconomic status, now it is also prevalent among lower socioeconomic status. ${ }^{8}$ Literature also suggest that people with lower socioeconomic status were more prone to complications associated with diabetes. $^{8}$

Family history, environmental factors, sedentary life style, obesity, age, and high blood pressure are important risk factor of diabetes. Good food habit, physical activities, and regular check-up can help people in controlling diabetes. Complications of diabetes are; cardiovascular disease, diabetic neuropathy, diabetic nephropathy, diabetic retinopathy, foot damage, skin conditions, hearing impairment, Alzheimer's disease, and depression.

More than $50 \%$ of Indian population still lives in rural areas. Knowledge and awareness about risk factor of diabetes, and its complications is very poor in north India. ${ }^{8}$ Thousand of people (patients and their attendants) are visiting eye care facilities every day. Eye care facilities can also play a pivotal role in educating people about diabetes, and its complications. Murthy et al. also highlighted the needs of an integrated approach where the eye care and diabetic care services work

\footnotetext{
* Corresponding author.

E-mail addresses: shikhasharma972064@gmail.com (S. Sharma), jayendrajha8@gmail.com (J. Jha), doctorabhishekvarshney@gmail.com (A. Varshney), lokesh.chauhan@rediffmail.com (L. Chauhan).
} 
Table 1

Sociodemographic characters of the study population.

\begin{tabular}{|c|c|c|c|c|c|}
\hline S.No & Particular & Diabetes aware & Diabetes not aware & Total & p-value \\
\hline \multirow[t]{3}{*}{1} & Gender & & & & \\
\hline & Male & $300(62.2 \%)$ & $31(64.6 \%)$ & $331(62.5 \%)$ & 0.74 \\
\hline & Female & $182(37.8 \%)$ & $17(35.4 \%)$ & $199(37.5 \%)$ & \\
\hline \multirow[t]{3}{*}{2} & Previously counselled & & & & \\
\hline & Yes & $181(37.6 \%)$ & $9(18.8 \%)$ & $190(35.8 \%)$ & 0.01 \\
\hline & No & $301(62.4 \%)$ & $39(81.2 \%)$ & $340(64.2 \%)$ & \\
\hline \multirow[t]{5}{*}{3} & Education Level & & & & \\
\hline & Illiterate & $133(27.6 \%)$ & $28(58.3 \%)$ & $161(30.4 \%)$ & 0.00 \\
\hline & Primary & $144(29.9 \%)$ & $7(14.6 \%)$ & $151(28.5 \%)$ & \\
\hline & Secondary & $109(22.6 \%)$ & $8(16.7 \%)$ & $117(22.1 \%)$ & \\
\hline & Graduation and above & $96(19.9 \%)$ & $5(10.4 \%)$ & $101(19.1 \%)$ & \\
\hline \multirow[t]{3}{*}{4} & Income & & & & \\
\hline & $\leq 10,000 \mathrm{INR}$ & $306(65.5 \%)$ & $40(83.3 \%)$ & $346(65.3 \%)$ & 0.01 \\
\hline & $>10,000 \mathrm{INR}$ & $176(36.5 \%)$ & $8(16.7 \%)$ & $184(34.7 \%)$ & \\
\hline \multirow[t]{3}{*}{5} & Family Member & & & & \\
\hline & $\leq 6$ members & $379(78.6 \%)$ & $33(68.8 \%)$ & $412(77.7 \%)$ & 0.11 \\
\hline & $>6$ members & $103(21.4 \%)$ & $15(31.2 \%)$ & $118(22.3 \%)$ & \\
\hline 6 & Age of participants & $53.4 \pm 10.3$ Years & $54.8 \pm 11.5$ Years & & 0.4 \\
\hline
\end{tabular}

together toward prevention and management of diabetes. ${ }^{9}$ Accordingly, this study aims to assess the knowledge, and awareness about diabetes and its complications among different strata of people attending a tertiary care eye institute in north India. This information is crucial in educating people about diabetes to reduce the future burden of this disease.

\section{Methodology}

The study was approved by the institutional ethics committee. The study adhered to the principles of declaration of Helsinki. A cross sectional survey among participants aged 18 years and above visiting tertiary care eye institute was conducted from January to March 2018. Participants were randomly selected from a pool of patient's attendants visiting our institute. Quality control system was implemented during data collection to ensure uniformity and accuracy of the data. Identified participants were invited to participate in this survey. The objective of the study was discussed and they were requested to sign the inform consent. Participants who signed the informed consent, or gave their thumb impression were enrolled in the survey. The participants were asked to answer each question face-to-face with one trained interviewer. Each interview took approximately $20-25 \mathrm{~min}$ and was conducted at a designated places which was comfortable to all participants. After the interview, general information about diabetes, and its risk factors, complications, and management was provided by the interviewer. Participants were considered aware if they were aware of the fact that diabetes could be identified by blood or urine tests. Participants were considered diabetics if they reported being on medication for diabetes.

In a previous Indian study, knowledge regarding diabetes was reported in $58.4 \%$ people. ${ }^{9}$ Based on those findings calculated sample size (prevalence, $\mathrm{p}=58.4 \%$ i.e. $0.584, \mathrm{q}=1-\mathrm{p}, \alpha=0.05$, allowable error, $\mathrm{d}=5 \%$ and applying formula $\mathrm{Z}_{\alpha}{ }^{2} \mathrm{pq} / \mathrm{d}^{2}$ ) for this survey was 374 . Assuming losses due to incomplete questionnaires at $20 \%$, the sample size was adjusted to 450. Pretested questionnaire was developed with the help of experienced faculty and literature search. ${ }^{10}$ Questionnaire consist of demographic factor, and questions to assess awareness, risk factor, prevention, and complication of diabetes. It also contains questions to assess barriers in diabetic screening. Questionnaire had nine questions to assess the demographics, eleven questions to assess the knowledge, risk factors, complications, prevention, two questions to assess socioeconomic status, and one question to assess their attitude about study intervention. Questionnaire was pretested on staff working at the institute to assess its internal consistency. However the data generated during pretesting was not included in the final analysis.
For the purpose of comparison, all the patients were divided in to two groups according to their awareness of diabetes. Participants who were aware of diabetes were further divided into diabetics and nondiabetics.

\subsection{Statistical analysis}

The statistical analysis was performed with SPSS 17.0 software (SPSS Inc, Chicago, IL, USA). Descriptive statistics were obtained to determine the frequency and proportions. Mean and standard deviation was calculated for continuous variables. Summaries of descriptive statistics and group comparisons are provided, which were made using the unpaired $t$-test for continuous data and the chi square test for proportions.

\section{Results}

Baseline characteristics of study population: 530 participants were interviewed. Out of them 331 [62.5\%, 95\% CI: 58.2\%-66.4\%)] were males and 199 [37.5\%, (95\% CI: 33.5\%-41.7\%)] were females. Average age of participants was $35 \pm 10.4$ years (Range: $35-91$ years). 161 [30.4\%, (95\% CI: $26.6 \%-34.4 \%$ )] of them were illiterate, 151 [28.5\%, (95\% CI: $24.8 \%-32.4 \%)]$ had primary education, 117 [22.1\%, (95\% CI: 18.7\%-25.8\%)] had secondary level, and 101 [19.1\%, (95\% CI: $15.9 \%-22.6 \%)]$ were graduate and above.

Awareness about diabetes: Of 530 participants, 482 [90.9\%, (95\% CI: $88.1 \%-93.1 \%$ )] were aware of diabetes (Group 1). Mean age of participants of group one was $53.4 \pm 10.3$ years. In group 1,300 [62.2\%, (95\% CI: 57.8\%-66.4\%)] participants were males, and 182 [37.8\%, (95\% CI: $33.5 \%-42.1 \%)]$ were females. All other characteristics are shown in Table 1. Forty eight [9.1\%, (95\% CI: 6.9\%-11.8\%)] participants were not aware of diabetes (Group 2). Mean age of group two participants was $54.8 \pm 11.5$ years. 31 [64.6\%, (95\% CI: $50.4 \%-76.5 \%)]$ participants of group two were male, and 17 [35.4\%, (95\% CI: $23.4 \%-49.5 \%)]$ were female. 28 (58\%) participants of group two were illiterate. (Table 2). A comparison of all characteristics between male and female of group 1 are shown in Table 3.

Associations of awareness of DM with various social demographic factors: In group one, 156 [32.4\%, (95\% CI: 25.3\%-33.6\%)] participants were diabetics, and 326 [67.6\%, (95\% CI: 63.3\%-71.6\%)] were non diabetics. Mean age of diabetic participants was $54.2 \pm 10.2$ years. Of them, $101(64.7 \%)$ were males, and 55 (35.3\%) were females. 71 [45.5\%, (95\% CI: 37.9\%-53.3\%)] diabetics participants were having family history of diabetes as compared to 99 [30.4\%, (95\% CI: $25.6 \%-35.5 \%$ ) ] non diabetic [p $=0.001$, Chi-square test (OR: $1.9 ; 95 \%$ 
Table 2

Characteristics and knowledge of the respondent who were aware of diabetes (Group 1).

\begin{tabular}{|c|c|c|c|c|c|}
\hline S.No & Characteristics & Diabetics & Non diabetics & Total & $\mathrm{p}$-value \\
\hline \multirow[t]{3}{*}{1} & Gender & & & & \\
\hline & Male & $101(64.7 \%)$ & $199(61 \%)$ & $300(62.2 \%)$ & 0.43 \\
\hline & Female & $55(35.3 \%)$ & $127(39 \%)$ & $182(37.8 \%)$ & \\
\hline \multirow[t]{3}{*}{2} & Previously counselled & & & & \\
\hline & Yes & $78(50 \%)$ & $103(31.6 \%)$ & $181(37.6 \%)$ & 0.00 \\
\hline & No & $78(50 \%)$ & $223(68.4 \%)$ & $301(62.4 \%)$ & \\
\hline \multirow[t]{3}{*}{3} & Family History of diabetes & & & & \\
\hline & Yes & $71(45.5 \%)$ & $99(30.4 \%)$ & $170(35.3 \%)$ & 0.01 \\
\hline & No & $85(51.5 \%)$ & $227(69.6 \%)$ & $312(64.7 \%)$ & \\
\hline \multirow[t]{5}{*}{4} & Education Level & & & & \\
\hline & Illiterate & $36(23.1 \%)$ & $97(29.8 \%)$ & $133(27.6 \%)$ & 0.00 \\
\hline & Primary & $48(30.8 \%)$ & $96(29.4 \%)$ & $144(29.9 \%)$ & \\
\hline & Secondary & $43(27.6 \%$ & $66(20.2 \%)$ & $109(22.6 \%)$ & \\
\hline & Graduation and above & $29(18.6 \%)$ & $68(20.6 \%)$ & $96(19.9 \%)$ & \\
\hline \multirow[t]{3}{*}{5} & Is diabetes prevalence increasin & & & & \\
\hline & Yes & $124(79.5 \%)$ & $263(80.7 \%)$ & $387(80.3 \%)$ & 0.75 \\
\hline & No/Don't Know & $32(20.5 \%)$ & $63(90.3 \%)$ & $95(19.7 \%)$ & \\
\hline \multirow[t]{5}{*}{6} & Frequency of diabetes check-up & & & & \\
\hline & 6 months & $93(59.6 \%)$ & $168(51.5 \%)$ & $261(51.4 \%)$ & 0.05 \\
\hline & 1 year & $31(19.9 \%)$ & $55(16.9 \%)$ & $86(17.8 \%)$ & \\
\hline & 2 year & $4(2.6 \%)$ & $6(1.8 \%)$ & $10(2.1 \%)$ & \\
\hline & SOS & $28(17.9 \%)$ & $97(29.8 \%)$ & $125(25.9 \%)$ & \\
\hline \multirow[t]{3}{*}{7} & Diabetes Complication & & & & \\
\hline & Aware & $139(89.1 \%)$ & $252(77.3 \%)$ & $391(81.1 \%)$ & 0.01 \\
\hline & Not aware & $17(10.9 \%)$ & $74(22.7 \%)$ & $91(18.9 \%)$ & \\
\hline \multirow[t]{7}{*}{8} & Organs that can affect by diabet & & & & \\
\hline & Eyes & $77(49.4 \%)$ & $151(46.3 \%)$ & $228(47.3 \%)$ & 0.53 \\
\hline & Heart & $23(14.7 \%)$ & $45(13.8 \%)$ & $68(14.1 \%)$ & 0.78 \\
\hline & Kidney & $65(41.7 \%)$ & $153(46.9 \%)$ & $218(45.2 \%)$ & 0.27 \\
\hline & Brain & $11(7.1 \%)$ & $29(8.9 \%)$ & $40(8.3 \%)$ & 0.49 \\
\hline & Lungs & $18(11.5 \%)$ & $34(10.4 \%)$ & $52(10.8 \%)$ & 0.71 \\
\hline & Feet & $11(7.1 \%)$ & $13(4 \%)$ & $24(5 \%)$ & 0.14 \\
\hline \multirow[t]{3}{*}{9} & Diabetic retinopathy awareness & & & & \\
\hline & Yes & $40(25.6 \%)$ & $45(13.8 \%)$ & $85(17.6 \%)$ & 0.01 \\
\hline & No & $116(74.4 \%)$ & $281(86.2 \%)$ & $397(82.4 \%)$ & \\
\hline \multirow[t]{3}{*}{10} & Awareness of risk factors of dial & & & & \\
\hline & Aware & $117(75 \%)$ & $257(78.8 \%)$ & $374(77.6 \%)$ & 0.34 \\
\hline & Not aware & $39(25 \%)$ & $69(21.2 \%)$ & $108(22.4 \%)$ & \\
\hline \multirow[t]{6}{*}{11} & Risk factors of diabetes & & & & \\
\hline & Family history & $39(25 \%)$ & $80(24.5 \%)$ & $119(24.7 \%)$ & 0.91 \\
\hline & High blood pressure & $26(16.7 \%)$ & $60(18.4 \%)$ & $86(17.8 \%)$ & 0.64 \\
\hline & Mental stress & $34(21.8 \%)$ & $61(18.7 \%)$ & $95(19.7 \%)$ & 0.42 \\
\hline & Sedentary life style & $15(9.6 \%)$ & $46(14.1 \%)$ & $61(12.7 \%)$ & 0.16 \\
\hline & Overweight & $43(27.6 \%)$ & $113(34.7 \%)$ & $156(32.4 \%)$ & 0.11 \\
\hline \multirow[t]{3}{*}{12} & Diabetes can be prevented & & & & 0.82 \\
\hline & Yes & $107(68.6 \%)$ & $221(67.8 \%)$ & $328(68 \%)$ & \\
\hline & No/Don't Know & $49(31.4 \%)$ & $105(32.2 \%)$ & $154(32 \%)$ & \\
\hline 13 & How diabetes can be prevented & & & & \\
\hline & Diet control & $65(41.7 \%)$ & $136(41.7 \%)$ & $201(41.7 \%)$ & 0.99 \\
\hline & Regular medications & $65(41.7 \%)$ & $139(42.6 \%)$ & $204(42.3 \%)$ & 0.84 \\
\hline & Regular exercise & $64(41 \%)$ & $131(67.2 \%)$ & $195(40.5 \%)$ & 0.86 \\
\hline 14 & Previous eye check-up & & & & \\
\hline & Yes & $104(66.6 \%)$ & $220(67.5 \%)$ & $324(67.2 \%)$ & 0.94 \\
\hline & No & $52(33.4 \%)$ & $106(32.5 \%)$ & $158(32.8 \%)$ & \\
\hline 15 & Barrier to diabetic screening & & & & \\
\hline & Access to healthcare facility & $25(16 \%)$ & $50(15.3 \%)$ & $75(15.6 \%)$ & 0.84 \\
\hline & Knowledge about diabetes & $60(38.5 \%)$ & $106(32.5 \%)$ & $166(34.4 \%)$ & 0.19 \\
\hline & Cost of healthcare & $27(17.3 \%)$ & $92(28.2 \%)$ & $119(24.7 \%)$ & 0.01 \\
\hline & Time & $43(27.6 \%)$ & $98(30.1 \%)$ & $141(29.3 \%)$ & 0.57 \\
\hline 16 & Is this discussion help in unders & & & & \\
\hline & Yes & $145(92.9 \%)$ & $301(92.3 \%)$ & $446(92.5 \%)$ & 0.81 \\
\hline & No & $11(7.1 \%)$ & $25(7.7 \%)$ & $36(7.5 \%)$ & \\
\hline 17 & Family Income & & & & \\
\hline & $\leq 10,000 \mathrm{INR}$ & $107(68.6 \%)$ & $199(61 \%)$ & $306(63.5 \%)$ & 0.11 \\
\hline & $>10,000 \mathrm{INR}$ & $49(31.4 \%)$ & $127(39 \%)$ & $176(36.5 \%)$ & \\
\hline 18 & Family members & & & & \\
\hline & $\leq 6$ members & $124(79.5 \%)$ & $255(78.2 \%)$ & $379(78.6 \%)$ & 0.75 \\
\hline & $>6$ members & $32(20.5 \%)$ & $71(21.8 \%)$ & $103(21.4 \%)$ & \\
\hline
\end{tabular}

CI: 1.3 to 2.8 )]. 124 [79.5\%, (95\% CI: $72.4 \%-85 \%)$ ] diabetic participants felt that prevalence of diabetes has been increasing. Among diabetics, 65 [41.7\%, (95\% CI: 34.2\%-49.5\%)] participants were diabetics from 0 to 5 years, 40 [25.6\%, (95\% CI: $19.4 \%-33 \%$ )] from 6 to 10 years, 25 [16\%, (95\% CI: $11.1 \%-22.5 \%)]$ from 11 to 15 years, and 26 [16.7\%, (95\% CI: $11.6 \%-22.3 \%)]$ from 16 to 20 years. Thirty seven [23.7\%, (95\% CI: $17.7 \%-30.9 \%)$ ] of them were type 1 diabetics, and 119 [76.3\%, (95\% CI: 69\%-82.2\%)] of them were type 2 diabetics. 
Table 3

Distribution of characteristics among males and females (Group 1).

\begin{tabular}{|c|c|c|c|c|c|}
\hline S.No & Characteristics & Male & Female & Total & p-value \\
\hline \multirow[t]{3}{*}{1} & \multicolumn{5}{|c|}{ Previously counselled } \\
\hline & Yes & $125(41.7 \%)$ & $56(30.8 \%)$ & $181(37.6 \%)$ & 0.02 \\
\hline & No & $175(58.3 \%)$ & $126(69.2 \%)$ & $301(62.4 \%)$ & \\
\hline \multirow[t]{5}{*}{2} & \multicolumn{5}{|l|}{ Education Level } \\
\hline & Illiterate & $67(22.3 \%)$ & $66(36.3 \%)$ & $133(27.6 \%)$ & 0.01 \\
\hline & Primary & $90(30 \%)$ & $54(29.7 \%)$ & $144(29.9 \%)$ & \\
\hline & Secondary & $73(24.3 \%)$ & $36(19.8 \%)$ & $109(22.6 \%)$ & \\
\hline & $\begin{array}{l}\text { Graduation and } \\
\text { above }\end{array}$ & $70(23.3 \%)$ & $26(14.3 \%)$ & $96(19.9 \%)$ & \\
\hline \multirow[t]{3}{*}{3} & \multicolumn{5}{|c|}{ Is diabetes prevalence increasing } \\
\hline & Yes & $243(81 \%)$ & $144(79.1 \%)$ & $387(80.3 \%)$ & 0.61 \\
\hline & No/Don't Know & $57(19 \%)$ & $38(20.9 \%)$ & $95(19.7 \%)$ & \\
\hline \multirow[t]{5}{*}{4} & \multicolumn{5}{|c|}{ Frequency of diabetes check-up } \\
\hline & 6 months & $168(56 \%)$ & $93(51.1 \%)$ & $261(54.1 \%)$ & 0.29 \\
\hline & 1 year & $49(16.3 \%)$ & $37(20.3 \%)$ & $86(17.8 \%)$ & \\
\hline & 2 year & $4(1.3 \%)$ & $2(3.3 \%)$ & $10(2.1 \%)$ & \\
\hline & sos & $79(26.3 \%)$ & $46(25.3 \%)$ & $125(25.9 \%)$ & \\
\hline \multirow[t]{3}{*}{5} & \multicolumn{5}{|c|}{ Diabetes Complication } \\
\hline & Aware & $243(81 \%)$ & $148(81.3 \%)$ & $391(81.1 \%)$ & 0.93 \\
\hline & Not aware & $57(19 \%)$ & $34(18.7 \%)$ & $91(18.9 \%)$ & \\
\hline \multirow[t]{3}{*}{6} & \multicolumn{5}{|c|}{ Diabetic retinopathy awareness } \\
\hline & Yes & $61(20.3 \%)$ & $24(13.2 \%)$ & $85(17.6 \%)$ & 0.04 \\
\hline & No & $239(79.7 \%)$ & $158(86.8 \%)$ & $397(82.4 \%)$ & \\
\hline \multirow[t]{3}{*}{7} & \multicolumn{5}{|c|}{ Awareness of risk factors of diabetes } \\
\hline & Aware & $239(79.7 \%)$ & $135(74.2 \%)$ & $374(77.6 \%)$ & 0.16 \\
\hline & Not aware & $61(20.3 \%)$ & $47(25.8 \%)$ & $108(22.4 \%)$ & \\
\hline \multirow[t]{3}{*}{8} & \multicolumn{4}{|c|}{ Diabetes can be prevented } & 0.01 \\
\hline & Yes & $217(72.3 \%)$ & $111(61 \%)$ & $328(68 \%)$ & \\
\hline & No/Don't Know & $83(22.7 \%)$ & $71(39 \%)$ & $154(32 \%)$ & \\
\hline
\end{tabular}

Awareness of risk factor of diabetes: 117 [75\%, (95\% CI: 67.6\%-81.1\%)] diabetic participants said that they were aware about risk factors of diabetes as compared to 257 [87.8\%, (95\% CI: $74.1 \%-82.9 \%)$ ] non diabetics $[p=0.41$, Chi-square test]. The most common risk factor identified by respondents were: overweight 156 [32.4\%, (95\% CI: $28.3 \%-36.6 \%)$ ]; family history 119 [24.7\%, (95\% CI: 21.1\%-28.7\%)]; mental stress 95 [19.7\%, (95\% CI: $16.4 \%-23.4 \%)]$; high blood pressure 86 [17.8\%, (95\% CI: $14.6 \%-21.5 \%)]$; and lack of physical activity 61 [12.7\%, (95\% CI: 9.9\%-15.9\%)].

Awareness of complications of diabetes: 139 [89.1\%, (95\% CI: 83.2\%-93.1\%)] diabetic participants were aware about at least one complication of diabetes as compared to 252 [77.3\%, (95\% CI: $72.4 \%-81.5 \%$ )] among non-diabetics [p $=0.003$, Chi-square test (OR: 2.4; $95 \%$ CI: 1.3 to 4.2)]. Among complications, the kidney was cited by 218 [45.2\%, (95\% CI: 40.8\%-49.6\%)], eyes 228 [47.3\%, (95\% CI: $42.8 \%-51.7 \%)]$, heart 68 [14.1\%, (95\% CI: $11.2 \%-17.5 \%)]$, lungs 52 $[10.8 \%$, (95\% CI: $8.3 \%-13.8 \%)]$, brain 40 [8.3\%, $(95 \%$ CI: 6.1\%-11.1\%)], feet 24 [5\%, (95\% CI: 3.3\%-7.3\%)]. Stomach was also cited by 23 [4.7\%, (95\% CI: 3.2\%-7.1\%)] respondent, and one participant said liver can be affected by diabetes.

Awareness of diabetic retinopathy: 40 [25.6\%, (95\% CI: 19.4\%-33\%)] diabetic participants were aware about diabetic retinopathy as compared to 45 [13.8\%, (95\% CI: $10.4 \%-17.9 \%)]$ non diabetics [p $=0.002$, Chi-square test (OR: $2.1 ; 95 \%$ CI:1.3 to 3.4)]. $20.3 \%$ (95\% CI: $16.1 \%-25.2 \%$ ) males were aware of diabetic retinopathy as compared to $13.2 \%$ (95\% CI: 9\%-18.8\%) [p = 0.04, chi square test]. 59 [69.4\%, (95\% CI: 58.9\%-78.1\%)] participants who were aware of diabetic retinopathy believe that individual with controlled diabetes can also develop diabetic retinopathy. 127 [81.4\%, (95\% CI: $74.5 \%-86.7 \%)$ ] diabetic participants were aware of that several other underlying medical condition can enhance the damaging effect of diabetes as compared to 221 [67.7\%, (95\% CI: $62.5 \%-72.6 \%)]$ non diabetic participants $[\mathrm{p}=0.001$, Chi-square test] .

Awareness about prevention: $107 \quad[68.5 \%, \quad(95 \% \quad$ CI: $60.9 \%-75.3 \%)$ ] diabetic participants felt that diabetes can be prevented as compared to 221 [67.8\%, (95\% CI: $62.5 \%-72.6 \%$ )] non diabetic participants $[\mathrm{p}=0.94$, Chi-square test $] .201 \quad[41.7 \%, \quad(95 \%$ CI: $37.3 \%-46.1 \%)]$ participants said that diabetes can be prevented by taking healthy food, 204 [42.3\%, (95\% CI: 37.9\%-46.7\%)] said that regular intake of medicine has been required, and 195 (40.5\%, (95\% CI: $36.1 \%-44.9 \%)$ ] said that it can be prevented by doing regular exercise.

Barrier to diabetic screening: $75[15.6 \%, \quad(95 \%)$ CI: $12.6 \%-19.1 \%)]$ participants felt that access to health care facility is the barrier in diabetic screening, 166 (34.4\%, (95\% CI: 30.3\%-38.7\%)] said knowledge about diabetes, 119 [24.7\%, (95\% CI: 21.1\%-28.7\%)] said that cost, and 141 [29.3\% (95\% CI: $25.3 \%-33.4 \%$ )] felt that time is the barrier. A total of 446 [84.1\% (95\% CI: 80.8\%-87.1\%)] participants felt that this questionnaire based discussion helped them in better understanding of diabetes.

\section{Discussion}

This study was conducted to assess the knowledge of people coming to a tertiary care eye institute regarding diabetes, its risk factors, complications and prevention. Majority of the participants were aware of diabetes. In general, they know that this is a disease related with sugar level in the body. Most of the people called this "sugar ki bimari" (in Hindi). This does not correlate to the study by Muninarayana et al. ${ }^{11}$ They reported that $50 \%$ of diabetic patients in south India had no knowledge of diabetes. Deepa et al. also reported awareness of diabetes among $43.2 \%$ people. ${ }^{10}$ Hussain et al. reported that $80 \%$ people were aware of diabetes. ${ }^{12}$ This may be because of the difference in selection of study population, and study area. Majority of the respondents had an opinion that prevalence of diabetes has been increasing.

The higher prevalence of diabetes among males across 15 states of India was reported by Anjana et al. ${ }^{5}$ The present survey reported that there was no difference between males and females regarding diabetes awareness. Although Deepa et al., reported higher awareness of diabetes among males. ${ }^{10}$ Most of the participants who were not aware of diabetes were illiterate and belonged to lower income group. Thirty five percent of the participants had attended at least one counselling regarding diabetes from a healthcare providers at any setup. Only $9 \%$ of them were not aware of diabetes in general. They do not know that this disease is related to sugar level. This indicate that the counselling done by healthcare providers can help in increasing the awareness of diabetes among population. Educating people to create awareness is the first step in diabetes prevention. ${ }^{13}$ There was no statistically significant difference between age of participants who were aware of, and who were not aware of diabetes.

Although $90 \%$ of the participants were aware of diabetes, but more than $50 \%$ of them were not aware of its complications. Only $14 \%$ of them were aware that diabetes can affect heart. Less than $10 \%$ of them know that it can also affect nerves. Deepa et al. also reported similar results. ${ }^{10}$ Less than $20 \%$ of all participants know that sedentary life style, and high blood pressure could lead to diabetes. However, more than $60 \%$ participants were aware that diabetes could be prevented, and around $40 \%$ of them know that it could be prevented by regular exercise and diet control.

Diabetic participants were more aware of complications of diabetes, and diabetic retinopathy as compared to non-diabetics. However there was no difference of awareness about risk factors, and prevention of diabetes between diabetic, and non-diabetic participants. Eyes, and kidney were the most cited organs that can be affected by diabetes. Namperumalsamy et al. also reported that most of the people surveyed felt that the eye was most commonly affected by diabetes. ${ }^{14}$ Heart, brain, and feet were also cited by many diabetic and non-diabetic respondents. Surprisingly; lungs, and stomach were also cited by few respondents. Lungs was cited by $11 \%$ diabetic respondents. This highlight that although people know about diabetes, they do not have complete knowledge about other aspects of diabetes.

Only $17 \%$ of the participants who were aware of diabetes, were also aware of diabetes retinopathy. Twenty five percent of the diabetic 
participants were aware of diabetic retinopathy. However Alzahrani et al., ${ }^{15}$ Almalki et al., ${ }^{16}$ Lingam et al., ${ }^{17}$ and Lian et al. ${ }^{18}$ reported high prevalence of awareness of diabetic retinopathy among diabetic people. Shah et al. reported that $63 \%$ of diabetics screened in their study were not aware of diabetic retinopathy. ${ }^{19}$ Males were more aware of diabetic retinopathy as compared to females. Illiterate females were least aware of diabetic retinopathy. Similar results has been reported by Hussain et al., ${ }^{12}$ and Bakkar et al. ${ }^{20}$

Family history of diabetes, and overweight were the major risk factors of diabetes cited by participants. High blood pressure, mental stress, and sedentary life style were also marked. Sixty percent of them mark more than one risk factor. There were no difference of awareness regarding risk factor of diabetes among diabetic and non-diabetic participants. Most of the participants were not aware of that diabetes can be prevented by healthy food, and daily exercise. Few of them said that diabetic people require regular medication to control diabetes.

$67 \%$ of the participants had their eye examination done previously. However $33 \%$ of diabetic participants had not underwent any eye examination by an ophthalmologist. This indicate the need of diabetic retinopathy screening among diabetic people in the study area. Counselling has been provided to them, that even if your vision is stable; you need an eye examination by an ophthalmologist. There are many potentially devastating eye problems that can develop without causing discomfort or distorting vision. Diabetic retinopathy, a serious complication that is more likely to occur in people with Type 1 diabetes but may develop in anyone with diabetes.

Knowledge about importance of regular checkup, available time for routine examination were the most common barrier marked by respondents in getting their diabetes/eye examination regularly. In this study, monthly income of $69 \%$ diabetic participants were less than 10,000 INR, compared to $61 \%$ of non-diabetic. Previously diabetes was thought to be a disease of rich people. ${ }^{[9]} 93 \%$ of the participants feels that this discussion would help them in better understanding of diabetes, its risk factors, complications, management, and prevention.

Diabetes education tool can be designed to empower diabetic patients; focusing on self-management, and possible complications of uncontrolled blood sugar. Since patients and relative spend time in waiting hall this tool can be distributed as a brochure for self-reading so that patients are more careful to monitor their blood sugar levels closely, adhere to the treatment regimen, and do regular physical exercise to control diabetes. This will help them to manage their own condition effectively.

Counselling sessions with family members of patients; who present or referred to the diabetic retinopathy clinic will help in educating them regarding diabetes.

This study shows that the majority of people visiting a tertiary eye care institute were aware of diabetes. However their knowledge about its risk factors, complications, prevention, and management was poor. Knowledge about diabetes, cost of treatment, and access to health care facility were identified as a barrier in diabetic screening. Educating people, affordable treatment, and easy access are the vital components in prevention, management, and control of diabetes. Eye care facilities can also be used in educating people and creating awareness about diabetes.

\section{Source(s) of support}

NIL.

\section{Declaration of interest}

\section{Acknowledgement}

None.

\section{Appendix A. Supplementary data}

Supplementary data to this article can be found online at https:// doi.org/10.1016/j.cegh.2019.05.002.

\section{References}

1. World Health Organization Deaths from Ncds. [(accessed on 20 April 2017)]; Available online:. http://www.who.int/gho/ncd/mortality_morbidity/ncd_total/en/.

2. World Health Organization. Global Status Report on Noncommunicable Diseases 2014 Geneva Switzerland: World Health Organization; 2015 2015-10-05 03:00:00.

3. International Diabetes Federation IDF Diabetes Atlas, 8th Edition. [(Accessed on 11 Mar 2018)]; Available online: http://www.diabetesatlas.org/resources/2017-atlas. html.

4. Anjana RM, Pradeepa R, Deepa M, et al. ICMR-INDIAB Collaborative Study Group. Prevalence of diabetes and prediabetes (impaired fasting glucose and/or impaired glucose tolerance) in urban and rural India: phase I results of the Indian Council of Medical Research-India DIABetes (ICMR-INDIAB) study. Diabetologia. 2011;54:3022-3027.

5. Anjana RM, Deepa M, Pradeepa R, et al. Prevalence of diabetes and prediabetes in 15 states of India: results from the ICMR-INDIAB population-based cross-sectional study. Lancet Diabetes Endocrinol. 2017:5:585-596.

6. Ramachandran A, Snehalatha C, Vijay V, King H. Impact of poverty on the prevalence of diabetes and its complications in urban southern India. Diabet Med. 2002:19:130-135.

7. Misra A, Pandey RM, Devi JR, Sharma R, Vikram NK, Khanna N. High prevalence of diabetes, obesity and dyslipidaemia in urban slum population in northern India. Int $J$ Obes Relat Metab Disord. 2001;25:1722-1729.

8. Rathod HK, Darade SS, Chitnis UB, Bhawalkar JS, Jadhav SL, Banerjee A. Rural prevalence of type 2 diabetes mellitus: a cross sectional study. J Soc Health Diabetes. $2014 ; 2: 82-86$

9. Murthy GV, Das T. Diabetic care initiatives to prevent blindness from diabetic retinopathy in India. Indian J Ophthalmol. 2016;64:50.

10. Deepa M, Bhansali A, Anjana RM, et al. Knowledge and awareness of diabetes in urban and rural India: the Indian Council of Medical Research India diabetes study (phase I): Indian Council of Medical Research India diabetes 4. Indian J Endocrinol Metab. 2014;1:379.

11. Muninarayana C, Hiremath G, Krishna I, Anil NS. Prevalence and awareness regarding diabetes mellitus in rural Tamaka, Kolar. Int J Diabetes Dev Ctries. 2010;13:18-21.

12. Hussain R, Rajesh B, Giridhar A, et al. Knowledge and awareness about diabetes mellitus and diabetic retinopathy in suburban population of a south Indian state and its practice among the patients with diabetes mellitus: a population-based study. Indian J Ophthalmol. 2016;64:272.

13. Deshpande AD, Harris-Hayes M, Schootman M. Epidemiology of diabetes and diabetes-related complications. Phys Ther. 2008;88:1254-1264.

14. Namperumalsamy P, Kim R, Kaliaperumal K, Sekar A, Karthika A, Nirmalan PK. A pilot study on awareness of diabetic retinopathy among non-medical persons in South India. The challenge for eye care programmes in the region. Indian $J$ Ophthalmol. 2004;52:247.

15. Alzahrani SH, Bakarman MA, Alqahtani SM, et al. Awareness of diabetic retinopathy among people with diabetes in Jeddah, Saudi Arabia. Ther Adv Endocrinol Metab. 2018;9:103-112.

16. Almalki NR, Almalki TM, Alswat K. Diabetics retinopathy knowledge and awareness assessment among the type 2 diabetics. Open Access Maced J Med Sci. 2018 15;6:574.

17. Lingam S, Rani P, Sheeladevi S, Kotapati V, Das T. Knowledge, attitude and practices on diabetes, hypertension and diabetic retinopathy and the factors that motivate screening for diabetes and diabetic retinopathy in a pyramidal model of eye health care. Rural Rem Health. 2018;18:4304.

18. Lian J, McGhee SM, Gangwani RA, Lam CL, Yap MK, Wong DS. Awareness of diabetic retinopathy and its association with attendance for systematic screening at the public primary care setting: a cross-sectional study in Hong Kong. BMJ open. $2018 \mathrm{Apr}$ 1;8(4):e019989https://doi.org/10.1136/bmjopen-2017-019989.

19. Shah K, Gandhi A, Natarajan S. Diabetic retinopathy awareness and associations with multiple comorbidities: insights from DIAMOND Study. Indian J Endocrinol Metab. 2018;22:30.

20. Bakkar MM, Haddad MF, Gammoh YS. Awareness of diabetic retinopathy among patients with type 2 diabetes mellitus in Jordan. Diabetes Metab Syndr Obes. $2017 ; 10: 435$.

None. 